\title{
Evaluating Inferences: the Nature and Role of Warrants
}

\section{Robert C. Pinto}

University of Windsor

\begin{abstract}
Résumé: Cet article suit les traces de David Hitchcock et de Stephen Toulmin pour avancer que les lois de passages (des raisons données à leur conclusion) sont des règles d'inférence matérielle. Il décrit la forme que de telles règles devraient prendre pour (a) appliquer l'idée qu'un argument est valide seulement s'il préserve le droit d'inférer, et pour (b) soutenir une version qualitative d' appui proportionnel. Cet article tente de décrire ce qui donne aux lois de passage leur force normative en examinant un concept de fiabilité adapté à l'explication de la forme que de telles règles devraient prendre.
\end{abstract}

Keywords: warrant; inference rule; material inference; evidence proportionalism; entitlement preserving inference; inferential practice; reliability; David Hitchcock; Stephen Toulmin

\section{Introduction}

This paper $^{1}$ explores two ideas:

(a) that there are material inferences-i.e. inferences whose "validity" does not depend on logical form ${ }^{2}$

(b) that rationality is a matter of making our attitudes toward propositions or propositional contents appropriate to the evidence which shapes them-developed in what might be called a qualitative version of evidence proportionalism. ${ }^{3}$ Though I think this conception of rationality can be applied in a very general way to illuminate the rationality of decisions and of such things as preferences, this paper will consider only how it can be worked out with respect to cognitive attitudes, and more specifically with reference to doxastic attitudes. ${ }^{4}$

The discussion that follows will be framed by an examination of two closely related versions of the proposal that we take certain generalizations which are not 
"logical truths" to be rules of inference (where 'logical truth' is unpacked after the manner of Quine 1953: 22-23) — versions offered by David Hitchcock and Stephen Toulmin, respectively. For the most part, I will ignore other attempts to deploy the idea of material inferences - in C. S. Peirce, ${ }^{5}$ Wilfrid Sellars ${ }^{6}$ or Robert Brandom, for example.

There are three questions that arise when one attempts to deploy the notion of "rules of inference" which are not logical truths, questions whose significance becomes salient when Hitchcock's and Toulmin's accounts are compared:

(a) What form should the statements that express such rules take? For example, in Hitchcock's account, they typically have the form of a certain kind of "covering generalization" which contains no explicitly normative expressions. In Toulmin, when warrants are "made more explicit" (Toulmin 2003/1958: 91) they contain normative expressions. This question is addressed in Part 2 of this paper, and reconsidered in Part 5.

(b) What virtues must arguments and inferences ${ }^{8}$ have if they are to be considered valid? Should we say that they must be truth-preserving? But then what about good arguments that aren't deductively valid and which have true premisses and a false conclusion? Can we say that they must at least be such that it's unlikely that their conclusions are false given that their premisses are true? But what about the possibility of "practical" arguments and inferences whose conclusions are intentions or prescriptions-things whose "propriety" does not consist in their being true? Or perhaps we can accommodate both defeasible inferences and practical inferences by saying, with Brandom, ${ }^{9}$ that what matters about inferences is whether they preserve "normative statuses"-for example, whether they are entitlement-preserving. But then what sorts of "entitlement" must be preserved by inferences that are valid and how is such an idea to be implemented? These questions are addressed in Parts 3 and 4 below.

(c) What virtues must rule statements have if they are to have normative force, if they are to be fit to serve as norms for arguments and inferences? This question is addressed in Part 6 below, though its significance will begin to emerge in Part 3.

\section{What form ought warrants to take? Hitchcock's account}

Building on work by Rolf George $(1972,1983)$ and beginning with his 1985 paper "Enthymematic Arguments," Hitchcock has been developing a "general theory of inference appraisal" (Hitchcock 2001: 1):

According to a current version of this theory, a conclusion follows (conclusively, provisionally, etc.) from premisses adduced in its support if 
and only if some covering generalization of the argument is non-trivially acceptable (always, provisionally, etc.).

Hitchcock himself has come to identify "the covering generalization of the argument" with Toulmin warrants quite explicitly (Hitchcock 1998: 27 and Hitchcock 2003). ${ }^{10}$

\section{Key features of Hitchcock's theory}

The core of Hitchcock's theory - carefully articulated and argued for in Hitchcock 1985 and 1998-offers an account of what it is for a conclusion to follow "conclusively" from its premisses. ${ }^{11}$ The general theory arises from the core theory by relaxing the requirement that the covering generalizations described in the core theory must be universal generalizations.

The theory has two components.

(a) The first component is a method for identifying, in the case of arguments that would typically be considered enthymemes, "the assumption" which the argument requires or presupposes (what has often been called its "missing premiss" or "implicit premiss").

(b) The second component is the claim that the identified assumption should not be considered a premiss of the argument, but should be considered a rule of inference that licenses the move from the explicit premiss or premisses to the conclusion.

The method for identifying "the assumption" of an argument is roughly as follows:

(i) Form the argument's associated conditional (a conditional statement whose antecedent is the conjunction of the argument's premisses and whose consequent is its conclusion)

(ii) Form a universal generalization with respect to at least one "repeated content expression"-where a "content expression" is defined in such a way that the standard logical particles are not content expressions and where a content expression is "repeated" if and only if it occurs more than once in premisses and/or conclusion. At least one of the content expressions over which one generalizes must occur in both premisses and conclusion ${ }^{12}$ - though not every content expression over which one generalizes need occur in both premisses and conclusion. ${ }^{13}$

Hitchcock calls a proposition formed in this way a covering generalization of the argument. For example, to use a stock example, the argument

Al Socrates is a man

Therefore Socrates is mortal

has just one covering generalization, and it may be expressed as follows:

For any value of $\mathrm{x}$, if $\mathrm{x}$ is a man then $\mathrm{x}$ is mortal.

Hitchcock formulates (1985: 89) a universal generalization thesis to the effect that: 
an enthymematic argument implicitly assumes the truth of a universal generalization of its associated conditional with respect to at least one repeated content expression.

But of course if there is more than one repeated content expressions in an argument, there will be several propositions that count as covering generalizations. Moreover, in some cases there can be concerns about the class over which we are generalizing. ${ }^{14}$ Accordingly Hitchcock (1985: 93-94) formulates a "fully qualified" version of the universal generalization thesis which provides guidance in picking out a universal generalization that might be called the generalization which an argument assumes.

Hitchcock suggests that the universal generalization thesis is confirmed by the fact that, to a considerable extent, the propositions it picks out as an argument's "assumption" coincide with or are logically equivalent to the propositions that we would intuitively pick out as its assumption. Thus it is significant that if asked for the assumption on which A1 depends almost nobody would offer the "logical minimum" ("If Socrates is a man, then Socrates is mortal"), and almost everybody would choose "All men are mortal" or something close to it.

Later presentations diverge from the 1985 paper with respect to covering generalizations in at least three respects.

(i) They do not attempt to pick out one of the possible covering generalizations and call it the assumption of the argument. There is no need to do this if our aim is evaluation, especially if we construe the covering generalization as a rule of inference rather than as a premiss. For we can say that an argument is valid (or that its conclusion follows from its premisses) whenever it has at least one covering generalization which is true or acceptable.

(ii) Later presentations include an important restriction on covering generalizations not included in the 1985 paper (or in the 1994 paper) that the truth or acceptability of the covering generalization must be non-trivial. ${ }^{15}$ Roughly, some substitution of repeated content expressions in the argument with which we started produces true premisses, and some substitution produces a false conclusion. See for example 1998: 24-26.

(iii) Finally, although the core theory presented in Hitchcock 1985 and 1998 requires or assumes that covering generalizations are universal generalizations, less restrictive accounts are offered in Hitchcock 1992 (esp. p. 112), 2003 (esp. p. 80) and 2005, p. 205, which states, "The requirement that the warrant be general is not a requirement that it be universal"' (italics mine).

Hitchcock 1985: 94-95 offers two lines of argument for construing the covering generalizations as rules rather than as premisses: 
(a) He points out problems that arise if we construe them as premisses and we also say that a premiss is either (a) a statement an arguer offers in support of her conclusion or (b) a proposition which the arguer "had in mind" in offering her argument. For there are enthymemes that appear to be perfectly good arguments, and in many cases the arguer doesn't actually have the covering generalization in mind.

(b) He points to the method of criticizing an argument by counter-example as evidence that we can evaluate an enthymematic argument without stating an implicit assumption.

In (1998: 31) he lists five benefits to be derived from regarding them as inference licenses rather than as premisses.

\section{Significance of Hitchcock's theory}

Hitchcock's theory is worthy of note for three reasons:

(a) it provides a principled way to identify a small list of potential rules (or warrants) for any argument or inference in which there is at least one content term that occurs in both premisses and conclusion;

(b) its generality and (if I may call it that) austerity enable Hitchcock to formulate clearly the question of whether certain "assumptions" are best conceived of as premisses or as inference rules (warrants), and to do so in a way that permits him to develop plausible arguments for conceiving of them as warrants;

(c) its generality and austerity will enable us to highlight issues I want to raise in this paper about the virtues arguments should possess, about the virtues inference rules should possess and about the form we should expect warrants or rules of inference to take.

To see both the appeal of Hitchcock's proposal, as well as the questions that arise concerning the virtues arguments should possess, consider the way Hitchcock formulates his "revised generic ${ }^{16}$ conception of consequence" (1998: 26):

There is some general feature of the argument which is incompatible with the argument's having true premisses and a false conclusion, even though that feature is compatible with the argument's having true premisses and compatible with the argument's having a false conclusion [italics mine].

Suppose for a moment that the principal virtue to be prized in arguments is that they be truth-preserving (i.e., that they do not lead from true premisses to a conclusion that's not true). A universal covering generalization which is true picks out a "general feature" of an argument on account of which it will have that virtue. Thus an evaluator, who wants to know whether an argument is truth-preserving, can assure herself that it is if she can find a universal covering generalization for that argument which is true. Notice also that, if an evaluator is in a position to know — of some covering generalization for the argument—-that it is true, she can 
make this determination without having first to determine the truth of the conclusion. ${ }^{17}$

\section{What virtues should arguments and rules of inference have?}

But now let's ask what virtue such covering generalizations (CGs) should possess. Begin by considering the CGs of the core theory, which are universal generalizations and which accordingly will be truth-preserving.

\section{Covering generalizations of the core theory}

Notice that there are different "variants" on the idea that the principal virtue of arguments and inferences is truth-preservation. Thus we might say that to qualify as a rule of inference it suffices

(i) that a universal CG be true with respect to the actual world.

Or, alternatively, we might demand some more stringent requirement. Thus, availing ourselves of "possible worlds" talk, we might opt for one or another of the following requirements:

(ii) that a universal CG be true in all "logically" possible worlds (i.e., worlds whose description would not be inconsistent with any logically true statement-where 'logical truth' is defined after the manner of Quine).

(iii) that a universal CG be true in all "semantically" possible worlds (i.e., worlds in describing which no "meaning postulate"-e.g., that "colored" applies to everything to which 'red' applies-is violated).

(iv) that a universal CG be true in all members of some interesting subset of semantically possible worlds-for example, the possible worlds in which what we currently believe to be laws of nature obtain. ${ }^{18}$

Thus on one occasion Hitchcock held that for an argument to be valid, its CG must be "lawlike" (1994: 59)—a view which we might take to commit him to something like (iv). One motive for opting for something like (iv) might be this: we want our principles of inference to include principles we can employ in reasoning from suppositions that are, or may turn out to be, contrary to fact. And generalizations that aren't lawlike don't "support" contrary-to-fact conditionals. ${ }^{19}$

A quite different approach to the virtue that inference rules should have can be found in Toulmin, who typically says that warrants must be reliable and that they derive their "authority" from backing which shows that they are reliable. It may well turn out to be the case that not all rules which are truth-preserving are fit to be relied upon, and that not all inferences which are fit to be relied upon are truthpreserving. Part 6 of this paper will offer a sketch of what we might take such reliability to consist in. 


\section{Covering generalizations of the general theory}

But notice that none of (i)-(iv) in the preceding section is going to work for good arguments/inferences that are not "conclusive"-inferences of the sort sometimes called "inductive" or (in a happier phrase) inferences in which the support that premisses lend to a conclusion is recognized as defeasible. The norms by which such inferences are assessed ought not to be rules that are truth-preserving, since such inferences can be good even when their premisses are true and their conclusions false. Hitchcock extends his core theory to handle such cases by loosening the requirement that covering generalizations be universal, and suggesting that a CG may be "possibly qualified as holding 'generally' or 'presumably"” (2003: 80 ), or that it is "non-trivially acceptable (always, provisionally, etc.)," or that it "can be modally qualified, as holding for the most part, or ceteris paribus, or even just sometimes" (2005: 205). Perhaps the clearest example of what he has in mind by such qualifications is to be found in Hitchcock 1992: 112, where he formulates a "conception of good inference" in the following terms (italics added):

The argument contains one or more repeated content expressions on which uniform substitutions within a category or subcategory some-times make the premises true, sometimes make the conclusion false, and either always, mostly, or provisionally make the conclusion true when they make the premises true.

The virtue which good arguments exhibit on this account is formulated with reference to truth, and we might say such arguments are good just when the truth of their premisses is indicative of the truth of their conclusions. ${ }^{20}$ But such formulations raise several questions which Hitchcock himself has not attempted to answer.

(a) It is not clear exactly what it means to say that of a set of substitutions that they "provisionally make the conclusion true" (Hitchcock 1992) or that a covering generalization can be qualified as "holding presumably" (Hitchcock 2003). This is something that needs to be spelled out in greater detail. ${ }^{21}$

(b) Though what it means to settle for "mostly" instead of "always" in the formulation of a covering generalization is clear enough, the implications of doing so need to be assessed. (1) Such "weakening" of criteria for the acceptability of a conclusion might well give rise to the sorts of problems associated with the attempt to formulate a purely probabilistic criterion of acceptance, such as the lottery paradox (see Pinto 2001: 106-107, especially footnote 5). And (2) chaining together a series of inferences that are not truth-preserving can lead to "untoward" results, and as a result it may turn out to be necessary to introduce epistemic operators into the consequent of covering generalisations (see the second of the two considerations presented in point (b) on p. 254 below). 
In Part 6 of this paper, following up on ideas suggested by Toulmin which Hitchcock himself doesn't draw on, I will attempt to work out a way of conceiving exactly how a CG may be qualified as holding only generally or presumably or provisionally, doing so in a way that addresses the issues just raised in points (a) and (b).

\section{Practical arguments and inferences}

Finally, we should note that even the more relaxed idea that arguments and inferences need only be truth-indicative isn't going to shed light on forms of argument that culminate in prescriptions or on forms of inference that culminate in a decision or an intention, since prescriptions, decisions and intentions don't have truth-values (i.e., their "direction of fit" is not word-to-world, but is world-to-word-see Searle 1979: 3-4 and section 32 of Anscombe 1957).

\section{Epistemic status}

In recent years Hitchcock has come to insist that CGs possess an additional sort of virtue. In (2001:1) he says that an argument's conclusion follows from its premisses if and only if it has some covering generalization that is "non-trivially acceptable (always, provisionally, etc.)," adding that a CG is acceptable if and only if it "deserves to be accepted by the appraiser." In (2003: 80) he says that an argument's conclusion or claim follows from its ground

if and only if there is some justified covering generalization of the argument,

possibly qualified as holding "generally" or "presumably" [italics added].

See also the discussion of "justified applicable warrant" in Hitchcock 2005. These texts all imply that a warrant must meet some sort of epistemic criterion.

I want to distinguish between the content of a rule or warrant, and the epistemic status which that content has for a particular person at a particular time. And, as I've already indicated in note 3 above, I want to set aside (or abstract from) questions about the epistemic status rules of inference must have-either for persons making an argument or drawing an inference, or for those appealing to the rule in the course of evaluating an argument or inference. I propose to deal here only with questions about the "content" of warrants—both (a) the form the content should take and (b) material features the content must have if it is to be fit to serve as a rule. And I want to press such questions especially in connection with cases in which the support licensed by such rules is defeasible.

\section{An alternative conception of argument virtue}

A common idea about arguments and inferences is that they provide justification for their conclusions. Of course bad arguments and inferences don't justify their conclusions, only good arguments do. It's possible to think of the justificatory potential of good arguments as simply a by-product of their meeting the criteria for 
being good. ${ }^{22}$ But it's also open to us to think that what makes an argument good is precisely its having justificatory potential. Let's try to make sense of the justificatory potential of arguments and inferences along the following lines:

A argument justifies its conclusion if and only if it shows-i.e., makes it apparent-that it is reasonable to embrace (perhaps to assert) that conclusion, given its premisses.

An inference justifies its conclusion if and only if it makes it reasonable to embrace (perhaps to accept) that conclusion, given its premisses.

If we follow up on these thoughts, we're led to a conception of argument virtue quite different from the conceptions just considered in Part 3. Let us endorse the idea that an argument is good only if it is reasonable to embrace its premisses. ${ }^{23}$ Then arguments or inferences with justificatory potential will be those in which premisses which it is reasonable to embrace render a conclusion reasonable to embrace. Such arguments need not be truth-preserving, but they will be entitlementpreserving.

In Part 6 of this paper, I am going to try to extract from Toulmin's account of arguments a rudimentary way of conceiving rules of inference consonant with the idea that the principal virtue of arguments is some sort of entitlement-preservation. But before attempting to do that, I want to provide motivation for the shift from truth-preserving norms to entitlement-preserving norms.

Why shift from a truth-preservation conception of argument virtue to an entitlement-preservation conception? Such a shift has potentially radical consequences, since it invites a move away from an approach to arguments and inferences that reduces to logic as traditionally conceived, toward an approach that will have to be grounded in epistemology. 'Reasonable' is not a word that belongs to the vocabulary of logic as traditionally conceived; it is a term whose elaboration will, almost inevitably, have to take place within an epistemological perspective.

In the case of good arguments which are "conclusive" and have "factual" premisses and conclusions, the shift to an epistemological perspective might turn out to be optional. But I want to suggest two reasons why such a shift may well be inevitable for any satisfactory treatment of defeasible arguments and inferences.

(a) Contemporary discussions of good arguments that aren't deductively valid highlight the fact that they are defeasible and attempt to conceptualize the relationship of such arguments to the considerations that "defeat" them-to the defeaters. But the notion of a defeater is, I submit, an ineluctably epistemic notion. Let $r$ be a consideration which can play the role of a defeater in connection with an inference from $p$ to $q$. $r$ does not defeat the inference from $p$ to $q$ by being true. ${ }^{24}$ Rather a defeater defeats an inference only in virtue of having a certain epistemic statusparadigmatically, by being or becoming known to be true--or what 
amounts to an epistemic status (e.g. being "in the database" or being derivable from what's "in the database"). Defeasible support for a conclusion is undermined or overridden by defeaters that have come to light.

(b) Even though we "accept" the conclusions of defeasible inferences, we must have some way of marking the fact that they are conclusions of defeasible inference- that they are, to put it crudely, "less than completely certain." Otherwise, we run the risk of stringing together a series of defeasible inferences with "untoward" results. Suppose we let $p$ lead to the acceptance of $q$, where propositions like $q$ are true $60 \%$ of the times at which propositions like $p$ are true; and suppose we also let $q$ lead to the acceptance of $r$ where propositions like $r$ are true $60 \%$ of the times at which propositions like $q$ are true. Then we will let $p$ lead to the acceptance of $r$, when the probability of $r$ given $p$ may be no more than .36-and that is an untoward result. The problem that threatens is not avoided by increasing the percentages - no matter how high the percentages get, stringing together such inferences "degrades" the support our initial premiss gives to our terminal conclusion and raises the possibility that a sufficiently long chain of such inferences will have an "untoward" outcome. It becomes essential therefore to mark the conclusions of defeasible inferences as such-which is, I think, what words like 'probably,' 'presumably,' 'possibly,' or 'almost certainly' are in fact doing when they're used to qualify our conclusions. The presence or absence of such markers will indicate when and how it is reasonable to use those conclusions as the premisses of further arguments. But to do that is just to perform the function which the vocabulary of epistemic evaluation performs.

These considerations are by no means conclusive. But I think they are enough to make it worthwhile to elaborate the idea of entitlement-preservation in greater detail. That's what I'll try to do in the remainder of this paper.

\section{The form of warrants revisited: an alternative account based on features of Toulmin's treatment of arguments}

One place we might look for examples of entitlement-preserving principles is in the accounts Chisholm used to give of epistemic principles. For reasons I won't pursue here, ${ }^{25}$ I think it will prove more instructive to extract explicitly entitlementpreserving principles from ideas and suggestions sketched in Toulmin 2003/1958 and Toulmin, Rieke and Janik (hereafter Toulmin et al.) 1984/1979. Accordingly, I'm going to construct an account of the form of warrants by picking and choosing from among elements of Toulmin's story. I take full responsibility for the result, but I acknowledge Toulmin as the source or inspiration of much (though clearly not all) of what I say. 


\section{Key features of Toulmin's account}

There are six features of Toulmin's account of arguments that I think any account of the form of warrants should incorporate or make provision for. They are as follows:

(i)Toulmin often formulates warrants as straightforward statements about objects ("Scarcely any Swedes are Roman Catholics") and says they may be written in the form "If D, then C." But he says that "they can profitably be expanded, and made more explicit" by putting them in a form such as "Data such as D entitle one to draw conclusions, or make claims, such as C" (2003/1958: 91-underlining is mine). Note two things about the second of the forms just quoted:

(a) it quite explicitly takes the form of granting an entitlement, as does another "expanded" statement form suggested in the very same passage: "Given data D, you may take it that C" 26

(b) it construes warranting statements as general statements-it is data such as $\mathrm{D}$ that entitle one to make a claim such as $\mathrm{C}$ (see Hitchcock 2003: 73-74).

(ii) Toulmin clearly distinguishes warrants from the "backing" which gives them authority by pointing to the normative and action-guiding force or function of warrants. Explaining the relation of backing to warrant with an example turning on a British statute, he says about the example:

Though the facts about the statute may provide all the backing required by this warrant, the explicit statement of the warrant itself is more than a repetition of these facts: it is a general moral of a practical character, about the ways in which we can safely argue in view of these facts (2003/1958: 98-italics mine).

(iii) He recognizes a crucial role for modal qualifiers ('probably', 'possibly,' 'certainly, 'presumably') in the presentation of arguments (2003/1958: 93ff). More importantly, he offers what I would call a functional interpretation of those qualifiers (2003/1958: chapters 1 and 2) - his insistence that the "field-invariant" force ${ }^{27}$ of such qualifiers is to be found "in the practical implications of their use" (p. 28) ${ }^{28}$ Thus on his interpretation, the force of saying "Possibly p" is to accord to $p$ the "right to be considered." And the force of saying "S is probably P" is to "commit myself guardedly, tentatively or with reservations to the view that $\mathrm{S}$ is $\mathrm{P}$, and (likewise guardedly) lend my authority to that view" 29 and he observes that the addition of the modal qualifiers "has the effect of indicating what sort of reliance the supporting material entitles us to place on the claim, C" (Toulmin et al. 1984/ 1979: 87).

(iv) In the Toulmin model, modals occur principally as qualifying the conclusion of an argument. However, Toulmin occasionally includes elements that correspond to such modal qualifiers in his formulation of warrants themselves. On the few occasions he does so, he uses expressions which convey explicitly that we are entitled to adopt a particular cognitive or doxastic attitude toward a propositional 
content. For example, in formulating a warrant whose backing consists of information about statutes, he chooses the following form of words: "If a man was born in a British colony, he may be presumed to be British" (2003/1958: 98). So phrased, the warrant recognizes an entitlement to adopt one particular cognitive attitude - presuming — toward a propositional content. ${ }^{30}$

There is a range of such attitudes-presuming that $p$, expecting that $p$ and being certain that $p$, for example - and I believe that each can be type-identified by reference to the functional role in our cognitive lives that it bestows on their contents. For example, an expectation that $\mathrm{X}$ will occur or has occurred provides a basis of inferences and actions that would normally be successful only if $\mathrm{X}$ will occur or has occurred. Someone who expects, but is not fully certain, that $\mathrm{X}$ has occurred or will occur can base actions or inferences on that expectation, but if she's not fully certain she will make backup plans to cover the eventuality that $\mathrm{X}$ might turn out not to be (or to have been) the case. Thus a reasonable person can expect (indeed be quite confident) that her lottery ticket won't win, and will make plans and undertake commitments on the assumption that it won't win, but can still hold on to the ticket because she knows it might be a winning ticket after all. (v) Under the heading of "rebuttals" Toulmin recognizes the role of defeaters in argument and inference. He seldom if ever includes a reference to rebuttals in his formulation of warrants, but rather treats them as matters which affect the applicability of warrants (2003/1958: 94-95; see also Toulmin et al., chapters 10, 11 and especially 13). ${ }^{31}$ The existence of defeaters needs to be acknowledged in the formulation of warrants, and though I won't purse the matter in this paper, a full account of warrants will have to shed light on the relationship of defeaters to the warrants whose force they defeat.

(vi) Toulmin treats the issue of whether a particular warrant has "authority" as (i) an issue whose resolution typically involves appeal to matters of fact (which make up the backing of the warrant) but also as (ii) an issue that must be addressed in light of the goals and purposes alive in the context of the reasonings that are to be assessed on the basis of that warrant. ${ }^{32}$

\section{An alternative account of the general form of warrants}

I want to make the idea of warrants for entitlement-preserving arguments and inferences more concrete. In order to do so, I offer a first sketch of the form such warrants might take. The sketch is a preliminary one, since it leaves a number of loose ends unresolved. But here are instructions for how to create a warrant of the sort I'm interested in. The process has five steps.

(1) Given an argument or inference, construct a covering generalization for it after the manner of Hitchcock. For simplicity's sake, assume the result is of the form

$\mathrm{H} 1$ ( $\mathrm{x}$ ) If $\mathrm{x}$ is $\mathrm{F}$ then $\mathrm{x}$ is $\mathrm{G}$ 
Of course, if there were more than one "repeated content expression" in the argument with which we started, we might chose to replace more than one of them with variables and prepend more than one universal quantifier.

(2) Next enhance H1 by inserting the phrase 'it is reasonable to suppose that' as follows:

$\mathrm{W} 1$ ( $\mathrm{x})$ If it is reasonable to suppose that $\mathrm{x}$ is $\mathrm{F}$ then it is reasonable to suppose that $\mathrm{x}$ is $\mathrm{G}$.

I am using supposing as a generic concept in relation to which believing, being almost certain, presuming, expecting, etc., stand as species. Notice that for quantification to work here, we have to be talking about de re supposing, not de dicto supposing. This should pose no problem, since supposing is something like believing, and we know how to manage with the distinction between de re and de dicto ascriptions of belief.

(3) But of course if supposing is anything like believing, what it's reasonable for one person to suppose can be quite different from what it's reasonable for another to suppose. So we need to complicate things a bit further, and include a reference to the person for whom a supposing might or might not be reasonable, and the time at which it is reasonable:

W2 (S) (t) (x) If it is reasonable at $t$ for $S$ to suppose that $\mathrm{x}$ is $\mathrm{F}$ then it is reasonable at $t$ for $S$ to suppose that $\mathrm{x}$ is $\mathrm{G}^{33}$

(4) Since we're taking supposing to be a generic expression of which presuming, expecting, being certain, etc., are forms or species, let us write our formula in such a way that it can accommodate a variety of different "species" of supposing, by introducing subscripts as follows

W3 (S) (t) (x) If it is reasonable at $\mathrm{t}$ for $\mathrm{S}$ to suppose ${ }_{i}$ that $\mathrm{x}$ is $\mathrm{F}$ then it is reasonable at $\mathrm{t}$ for $\mathrm{S}$ to suppose ${ }_{j}$ that $\mathrm{x}$ is $\mathrm{G}^{34}$

The intent is that in formulating a potential warrant for a particular argument or inference, we may specify one form of supposing in the antecedent of the warrant and specify either the same or a different form of supposing in the consequent of the warrant.

This provision will enable us to provide what I earlier called a "qualitative" equivalent to the idea that belief should be proportioned to the evidence.

(5) Finally, we need to include a qualification that recognizes the role that defeaters play in our reasoning about most matters. I propose to do that by including such a qualification, as follows

W3a (S) (t) (x) If it is reasonable at $\mathrm{t}$ for $\mathrm{S}$ to suppose $_{i}$ that $\mathrm{x}$ is $\mathrm{F}$ then, in the absence at $t$ of undermining or overriding evidence, it is reasonable at $\mathrm{t}$ for $\mathrm{S}$ to suppose $_{j}$ that $\mathrm{x}$ is $\mathrm{G}$. 
The underlined phrase is a "dummy" clause that, in effect, recognizes the existence of a set of problems which need to be solved.

\section{Significance of the alternative account}

The result is a form of warrant which

(a) is consistent with the idea that good arguments are entitlement preserving;

(b) construes the entitlements in question as epistemic entitlements;

(c) incorporates a qualitative version of "evidence proportionalism" by enabling us to licence only doxastic attitudes toward conclusions that are appropriate to the evidence on which those conclusions are based;

(d) makes explicit provision for defeasible arguments and inferences.

W3 and W3a are of course elaborations of an idea originally drawn from Hitchcock. But elaborating Hitchcock's idea in the way that I have brings us to something that's closer to the way Toulmin sometimes expresses his warrants. Recall for instance the example quoted in the previous section:

If a man was born in a British colony, he may be presumed to be British.

To recast that in the form of W3 we need only construe the word "may" as granting epistemic permission, and make it explicit that what creates the epistemic permission to presume is the knowledge that a man was born in a British colony.

Rules like these are quite different from the sorts of rules that logicians formulate. To understand their significance, I suggest we recall the "maxim of shallow analysis" that Quine (1960: 160) says should govern our paraphrases into "canonical systems of logical notation":

... expose no more logical structure than seems useful for the deduction or other inquiry at hand.

If rules whose form is captured by W1 through W3a are to be commended, it is because often not enough structure is exposed in the canonical notations of more traditional logics to enable us to offer nuanced evaluations of the arguments and inferences that interest us. Indeed, we might want to observe a modified version of Quine's maxim:

Move up from rules of the form of $\mathrm{H} 1$ toward rules of the form of W3a only when, and to the extent that, it is useful to expose more structure in order to achieve an appropriately nuanced evaluation.

Two final notes about the "general form of warrant" that W3 and W3a represent.

(a) Observe that warrants in which the "species of supposing" referenced in the antecedent and the consequent are the same will form a special case of this more general form-they will be "entitlement-preserving" in a narrow sense. Where a single premiss is known to entail its conclusion, for example, warrants will usually be entitlement-preserving 
in that narrow sense. But arguments and inferences that are not "deductively valid" will usually require warrants which are entitlementpreserving only in a broader sense captured by the general form of W3. What is preserved is these cases is reasonableness-but the kind of "doing" which is pronounced reasonable in the antecedent (e.g, being sure that) is a different kind of "doing" from that pronounced reasonable in the consequent (e.g., expecting).

(b) Notice also that we could make the form of warrant I'm proposing more general still by recasting it to accommodate propositional attitudes other than (but in addition to) doxastic attitudes-e.g., conative and evaluative attitudes such as desiring it to be the case that, intending that, fearing that, etc. See for example my 1990 paper "Generalizing the notion of argument," reprinted as Chapter 2 of Pinto 2001. Doing so would yield an even more powerful tool, one which would enable us to conceptualize the role of reasons in the constitution of emotions, in the formation of values and of intentions, and in the deliberation that issues in our practical choices.

\section{What virtues should warrants have?}

Taking my cue from Toulmin's frequent reference to the reliability of warrants, I want to offer a sketch of the virtue such warrants should have by offering an account of what we might take the reliability of a warrant to consist in. Though I think the account that follows is consistent with many of the things Toulmin says about how warrants acquire their authority, the account is quite specific to the conception of warrants sketched in Part 5 of this paper and in its details is almost certainly not anything which Toulmin himself ever actually had in mind.

\section{Rules and practices}

I'll use an example of a type of inference my spouse taught me to make. She's fond of Courtland apples, and often asks me to pick up a few when I shop for groceries. The first time I did, she complained that the apples I brought home were sour-she only likes the sweet ones. When I asked how I could tell whether a Courtland is sweet, she said something like following, pointing to a Courtland apple she'd just taken out of the refrigerator:

Look at the coloring of the skin. If it there's a fair amount of red in its skin, as there is in this one, you can assume that it's sweet.

She warned me that although this works with Courtland apples, it doesn't work for every kind of apple. A bit of probing revealed that she had discovered this technique herself by trial and error, and that she continues to use the technique because it works for her. Probing also revealed that, although she is aware that not 
all Courtland apples with this sort of coloring are sweet, she has no idea what proportion of them are sweet. Moreover, she doesn't know whether this technique works with Courtland apples generally; she only knows that it works in the places where she shops for apples.

It's also worth noting that although she uses this technique in deciding which Courtlands to buy, before she'd serve Courtland slices to guests, she would actually taste a slice from each apple to "make sure" that slices from that apple aren't sour. In other words, she treats the expectation arising from her inference as sufficient for some purposes (buying) but not for others (serving to guests).

My spouse had supplied me with a rudimentary "rule of inference" which, at the risk of pedantry, we can formulate as follows:

If you know (i.e., have the right to be sure) that the skin of a Courtland apple has a coloring similar to a particular sample, then it is reasonable for you to expect that it will be sweet.

Notice the following things about this "rule"

(a) It endorses an inferential practice in which my wife engages, and which she has taught me to engage in.

(b) That practice is sustained or reinforced because it regularly gets my spouse and me where we want to go, and it would be extinguished if it ceased regularly getting us where we want to go-if we started to find more than occasionally that the Courtlands we brought home weren't sweet.

(c) The possibility of such reinforcement and extinction depends on the fact that we have other ways of finding out whether an apple is sweetby biting into them, etc. But those other ways of finding out also have an "inferential dimension" (does this apple taste sour because it actually is sour, or am I coming down with a bug in virtue of which nothing would taste sweet to me) - that is to say, those other ways of finding out are sustained by other inferential practices. Inferential practices face the tribunal of experience not singly but as corporate bodies, somebody might say.

(d) The rule which endorses our inferential practice is not a rule that my spouse or I need to formulate explicitly or to follow consciously when we draw conclusions about the sweetness of Courtland apples in the store. In Sellars' happy phrase (1968: 75-77), it is not a rule for doing, it's a rule for criticizing. In cases like this, the practices may come first, the rules may get formulated in our attempt to get a "reflective hold" on them-perhaps for purposes of evaluating the practice or some instance of the practice.

(e) In cases like this one, finding a rule involves finding a description which fits one or another of our inferential practices-which is something 
that Hitchcock's technique for generating covering generalizations enables us to do, and which my elaboration on Hitchcock's technique also enables us to do. But acknowledging such a description as a rule involves, in addition, a decision to endorse one or another of our practices and to endorse it under some such description.

We can begin to understand the authority of such norms - and the virtues to be expected of them when they are formulated as rules-by reflecting on the considerations that should lead us to endorse one or another of our practices under a rule-like description of it.

\section{The context of rules: critical practice}

I suggested in the preceding section that inferential practices like those in my example are reinforced or extinguished depending on whether they regularly "get us where we want to go." Now reinforcement and extinction may be reasons why we engage in or cease to engage in inferential practices, but they are not reasons for engaging in such practices.

Reasons for engaging or not engaging in a practice begin to emerge only when we start to reason about our practices. To reason about our inferential practices, we need to get some kind of "reflective hold" on what they are. And formulating a rule-like description is one way of doing that-we can say, for instance, that we often behave as though we were following a rule that permits us to do X when $\mathrm{Y}$ obtains. But then the decision to endorse a practice can take the form of deciding (or perhaps finding out) whether following (or conforming to) such a rule would be a good thing to do.

Even though we may never have had any such rule actually in mind when engaging in an inferential practice - and even if we never start having it in mind at such times - the rules we reflectively endorse can become rules of criticism to which we can revert when evaluating what an actual person does on a particular occasion.

The emergence of a practice of reasoning about our inferences and our inferential practices changes things in important ways (see Sosa for a similar point ${ }^{35}$ ). It institutes a new kind of practice - a critical practice ${ }^{36}$ - in which we evaluate individual performances by measuring them against rules we've reflectively endorsed. Moreover, and perhaps most importantly, it permits us - as Brandom points out ${ }^{37}$ - to discuss the merits of the practices we engage in and to ask for and give reasons for endorsing them. Finally, the reflective practice of reasoning about our inferential practices introduces a new kind of "reinforcement" and "extinction": the realization that our practice would be better if it were changed in a certain way gives us reasons for changing our practices that can become reasons why they change. 


\section{Reliabilty}

So we find ourselves staring at the question: what would reasons for endorsing an inferential practice have to look like? Or - and this is not quite the same questionwhat would make an inferential practice a good one? The issues here are very much like the issues raised in Parts 3 and 4 about the virtues of arguments and inferences, but we're now playing in a slightly different key—we're asking about the virtues of inferential practices. Shifting into this key, two sorts of consideration now become possible:

A What role does one or another practice play in the broader scheme of things?

B How well do the "outputs" of a practice serve the role or roles which that practice plays?

Identifying the role of a practice provides an objective basis or criterion for making a value judgement about the outputs of the practice — in light of something like the principle that it's good when something serves its purpose and bad when it fails to serve its purpose. ${ }^{38}$

The purposes served by the sorts of inferential practices I'm considering in this paper must, in the nature of the case, be purposes which require the adoption of a doxastic attitude toward a propositional content. They must be purposes which require the fixation of belief about some matter, as it were. Now some purposes served by the adoption of doxastic attitudes are insensitive to whether the propositional content of the doxastic attitudes serving them are true or close to the truth-for example, loyalty to a friend may perhaps require I believe him to be innocent of some charge irrespective of whether or not he is. Such purposes can indeed give rise to "reasons for belief" of a special sort-which I have elsewhere called pragmatic reasons ${ }^{39}$ - but they are not the sorts of purposes in relation to which the reliability of inferential practices ought to be judged. Accordingly, I assume that any purpose in light of which the reliability of an inferential practice is properly judged must be a purpose

(1) which requires the adoption of a cognitive (e.g., doxastic) attitude, and

(2) whose realization is sensitive to whether the propositional content of the required cognitive attitude is true or close to the truth.

Thus, for any inferential practice whose outputs belong to a particular series of doxastic attitudes (being certain that $p$, presuming that $p$, expecting that $p$, for example), typical purposes won't be served unless there is a substantial likelihood that $p$ is true or close to the truth in the range of occasions in which the practice is appropriate. ${ }^{40}$ For inferential practices whose outputs belong to a different series of doxastic attitudes (for example, suspecting that $p$, treating $p$ as a "live option"), typical purposes will require only that there be a non-negligible likelihood that $p$ is true or close to the truth in the range of occasions in which the practice is appropriate. 
In Pinto 2003b I argued for the claim that rational decisions about whether to accept a proposition as a basis for further inferences, though made in light of evidence, are also dependent on epistemic and non-epistemic goals and purposessince (among other things) the "strength" of evidence needed to warrant acceptance of a premiss will depend in part on what's at stake in the reasoning which will be based on that premiss. ${ }^{41}$ Something similar is true with respect the rationality of adopting doxastic attitudes toward propositional contents. The purposes requiring the fixation of belief on a given matter can be either "practical" or "theoretical," and in either case are relevant to determining whether a given constellation of evidence warrants adoption of a given doxastic attitude.

Moreover, when the purposes served by an inferential practice require a substantial likelihood of truth or verisimilitude, the doxastic attitude issuing from the practice should also serve the purposes of the practice even when truth or verisimilitude is not achieved. Suppose that the output of an inference is an expectation or a presumption in which what is expected or presumed proves false. In many (perhaps all) such cases in which the expectation or presumption is reasonable, it will still have served my broader purposes well despite its content having proved false. If I plan a picnic because I expect it will be sunny, but make backup provisions for the eventuality that it might rain (because I only expect it will be sunny and am not certain of it), my doxastic attitude will have served me well even when it rains. Without an expectation of some sort concerning the weather I would have made no plans at all. Even in matters theoretical, a presumption-for example, the presumption that the gauges I'm employing in my experimentation are functioning properly-can serve me well even if it "fails" (e.g., if the gauges don't function properly). For the variation in the type of reliance I place on different elements of my experimental design gives me a "plan of attack" when the results I'm getting don't add up (I check the gauges first, before I start questioning the second law of thermodynamics). And without some such presumption there would have been no experiment in the first place, and hence no second iteration in which the problem with the gauges has been taken care of.

But if considerations like these put us in a position to make objectively based, nuanced assessments of inferential outputs, they put us in the position to ask the following question about an inferential practice:

C How reliably does the practice yield outputs that serve the role that it is playing?

This question must be interpreted as equivalent to something like the following:

$\mathrm{C}^{\prime}$ What is the objective likelihood that the output of the practice will be a good output, where goodness is judged in light of the role that the practice is playing?

The very idea that a practice is reliable — is fit to be relied upon—already contains the idea of the objective likelihood of a good output. 
Now it is important to note that an objective likelihood can only be calculated with respect to a reference class..$^{42}$ I submit that the appropriate reference class for determining the objective likelihood of successful outcome for an inferential practice must be fixed by reference to the typical circumstances in which that practice has been or will be relied upon.

As a result, the reliability of an inferential practice-for example, of expecting a Courtland to be sweet when we know that its skin exhibits a certain color patternwill depend on an objective likelihood. But the objective likelihood on which it depends will not be identical with the objective likelihood that a Courtland is sweet given that its skin exhibits a certain color pattern. Rather it will be the objective likelihood of (i) arriving at an appropriate doxastic attitude when (ii) relying on the practice in the typical circumstances in which it has been or will be relied upon.

A reliable warrant can be defined as one which licences a reliable inferential practice. $^{43}$

\section{Significance of this account}

The upshot of these points is an account which makes the "fitness" of a rule to serve as a warrant depend in part on the non-epistemic values of those whose reasoning is to be evaluated by reference to them, as well as on the sorts of situations in which the inferential practices it licences will actually be exercised. The account therefore makes the reliability of warrants highly context-sensitive. For these two reasons it might be called a pragmatic account of the virtue of rules of inference. But the position I'm defending is not a "subjectivism" about warrants, since it makes the authority of warrants depend on the objective likelihood of good outcomes and it makes the evaluation of outcomes depend on objective considerations. Moreover, even though it makes the authority of warrants depend in part on the non-epistemic values served by inferential practices, it does not do so in a way that runs afoul of Siegel's critique of the "means-ends conception of rationality", ${ }^{44}$ nor is it subject to Siegel's arguments against those who construe epistemic normativity as a crude form of instrumental rationality. ${ }^{45}$ Finally, because the position carefully distinguishes between entitlement-preserving rules and truthpreserving rules, it can embrace a pragmatism about rules without embracing a pragmatist account of truth and without foreswearing a realist account of the contents of our doxastic commitments.

\section{Conclusion: direction of further research}

What I've presented here is an initial sketch of a possible way of doing things. There are at least three respects in which this way of doing things needs to be elaborated by offering much more detailed accounts of elements that it invokes.

(a) The account depends crucially on the concept of functionally typeidentified doxastic attitudes, and I haven't done much more than hint at 
how attitudes like expecting, presuming, being certain, suspecting, etc., can be characterized and differentiated from each other in functional terms. Until I show that such a characterization is realizable in sufficient and compelling detail, it will remain unclear whether the variant on "evidence proportionalism" I' $m$ attempting to float here fares any better than the more traditional forms of evidence proportionalism which require us to assign numeric values to degrees of support and degrees of belief. (b) In trying to sketch the form that warrants should take, I wave my hand in the direction of defeaters by including the clause "in the absence of undermining or overriding evidence" in W3a. That's a little better than saying "other things being equal," but not much! It remains to be demonstrated that this clause can be unpacked in a coherent manner that is both consistent with the overall story I'm telling and is not objectionably circular.

(c) My discussion of the authority and reliability of warrants offers no more than a very preliminary sketch of a complicated topic. My principal example was of an inferential practice that is quite local, does not exhibit "field dependence" as that term has come to be widely understood, and is known to be reliable because it has worked in practice for a few individuals (and not by appeal to the sort of backing which Toulmin typically cites as lending warrants their authority). In those respects, my example is far from typical.

Moreover, in appealing to the purposes served by inferential practices, I have left it open whether the standard appealed to should be the purposes which, on one or another occasion, motivate individuals to rely on an inferential practice or whether it should be the purposes which motivate a cognitive community ${ }^{46}$ to institute or endorse an inferential practice.

A fully satisfactory account of the authority and reliability of warrants would need (i) to consider the differences between the "casual" or "occasional" sort of warrant that served as my example and the "standing warrants" which tend to be "field dependent," (ii) to examine carefully the variety of specific ways in which warrants are and should be scrutinized when doubts are raised about their authority, and finally (iii) to address the question of when the output of an "objectively" reliable inferential practice is "subjectively" justified. 


\section{Notes}

${ }^{1}$ This is a significantly revised version of a paper originally presented at a conference of the Ontario Society for Studies in Argumentation, held at McMaster University in May of 2005. I'm indebted to David Hitchcock, Harvey Siegel, Ralph Johnson, Tony Blair and David Godden for critical comments on earlier versions of this paper. Their comments have occasioned substantive changes in the paper.

${ }^{2}$ Trudy Govier (1987: 178) distinguishes between formal validity, deductive validity and what she calls umbrella validity. She defines umbrella validity as follows: "An argument is valid if and only if its premisses are properly connected to its conclusion and provide adequate reasons for it. It is invalid otherwise." When in this paper I refer without qualification to validity, it is umbrella validity that I am referring to.

${ }^{3}$ I am particularly interested in this idea as an alternative to the approach to argument in Goldman 1999: Chapter 5-an approach dominated by the idea that the social value of argument lies principally in its potential for disseminating true beliefs. (Goldman defends the primacy of truth as an epistemic virtue in Goldman 2002.) My dissent is motivated in part by my Popperian conviction that what it is reasonable to aim for in many if not most situations is something other than literal truth - it is closeness to the truth (Popper famously called it verisimilitude) — and that rationality requires that our doxastic attitudes reflect this fact.

Goldman 1988: 89-93 challenges the centrality of the idea that "credal states" must be appropriate to the strength of evidence-a view he calls "evidence proportionalism." He principally has in mind the view that the "degree of belief" one has in a proposition ought to be proportioned to the strength of the evidence which supports that proposition-usually with the assumption that numeric values can be assigned both to degrees of belief and to strength of evidentiary support. The idea I am interested in might be described as a qualitative variant on evidence proportionalismthe idea is that the sort of doxastic attitude one adopts toward a proposition should be appropriate to the evident reasons which favor it (where doxastic attitudes are assumed to be type-identified by the functions they allow propositions to play in our cognitive lives). Goldman's criticism of evidence proportionalism is quite explicitly framed so as to apply to views like the one I am interested in, views which don't involve assigning numeric values to belief and to support (he says on p. 90 that he will "assume whatever repertoire of credal states the evidence proportionalist wishes to postulate..."). Goldman's criticisms turn on the claim that "proportioning" belief to evidence is not a sufficient condition of epistemic justification, since either (i) the proportioning may have occurred by accident or else (ii) the belief may have been arrived at by a valid method which the believer has no reason to suppose is a valid method.

In the exposition that follows, I attempt to sidestep the issues Goldman raises by simply bracketing the question of when an individual is "subjectively justified" in adopting a conclusion or a particular attitude toward it. My rationale for this strategy is that in this paper I am trying to address the following two issues: (i) what should a rule of inference look like and (ii) when is such a rule "objectively" a good rule.

${ }^{4}$ In my paper "Generalizing the notion of argument" (reprinted as Chapter 2 of Pinto 2001), I urged that the study of argument should be broadened to include, not just reasons for adopting doxastic attitudes, but reasons for adopting conscious attitudes generally. In Pinto 2003c I proposed classifying conscious attitudes as cognitive, conative and evaluative-a classification which reflects Rescher's recognition (Rescher 1988: 3) of three types of rationality: cognitive rationality (whose "product" is factual contentions or beliefs), practical rationality (whose "product" is action recommendations or injunctions), and evaluative rationality (whose product is evaluation or appraisal). In Pinto 2003c: 6-7, I recognized three distinct categories of cognitive attitude toward propositions: (a) doxastic attitudes (belief and belief-like states such as presuming, expecting, etc.), (b) acceptance attitudes (which concern whether one is prepared to use a proposition as a 
premiss from which to draw conclusions in a given context) and (c) degrees of confidence (perhaps as measured by the odds at which we are willing to bet on the truth of a proposition). Acceptance attitudes (and maybe degrees of confidence as well) are context-dependent, but doxastic attitudes are not (see Appendix B of 2003c).

${ }^{5}$ See for example the notion of a "guiding principle" in "The Fixation of Belief"(Peirce 1955: 8ff.) and the entry entitled "What is a leading principle?" in Peirce 1955, 129-34.

${ }^{6}$ Most notably see Sellars discussion of "material inferences" in 1953 ("Inference and Meaning") and in "Some Reflections on Language Games" (which originally appeared in 1954, but is reprinted as Chapter 11 of Sellars 1963).

${ }^{7}$ See Brandom's insistence, following Sellars, on the importance of "material inferences" in Chapter 2 of Brandom 1994 and chapter 1 of Brandom 2000. Note his suggestion that: "the notion of formally valid inferences is definable in a natural way from materially correct ones, but there is no converse route" (2000: 55). Though Brandom's discussion of material inferences is quite explicitly derivative from Sellars, and though material inferences play an essential role in Brandom's project, he does not follow Sellars in associating them with lawlike statements and subjunctive conditionals. Brandom 1994: 634 observes that although "the difference between inferential connections among concepts that are counterfactually robust and those that are not is an important one....nothing is made of it here. This is partly because the notion of nomologicality and counterfactual reasoning, important though they are in other contexts, has not been reconstructed in scorekeeping terms as part of this project...." On p. 635 he explains in greater detail why he chooses not to do so.

${ }^{8}$ Following Pinto 2001: 36-37, I take arguments to be invitations to inference and I take the "logical appraisal" of an argument to consist in the appraisal of the inference it invites. The arguments and inferences whose virtues I'm asking about are limited to what Blair 2003: 1-2 calls atomic arguments and to the sorts of inference that are invited by atomic arguments.

${ }^{9}$ Brandom 1994: Chapter 3 introduces commitment and entitlement as normative or deontic statuses (p. 159), and distinguishes between inferences which are commitment-preserving and those which are entitlement-preserving (pp. 168ff.). In Chapter 4, entitlement gets linked to the "being justified" that makes for knowledge as opposed to mere belief-p. 201, but see all of Section I of Chapter 4 (pp. 199-206). The concept of an entitlement-preserving inference came into focus for me from my reading of Brandom. However, Brandom's views are controversial, and I am certainly not in full agreement with everything he says. Accordingly, nothing in this paper presupposes the truth of any of Brandom's views, and I've written the paper so that it does not presuppose familiarity with his views.

${ }^{10}$ As I see it, the key papers in this series are Hitchcock 1985, 1992, 1994, 1998 and 2003. In addition, Hitchcock 2001 and Hitchcock 2005 contribute additional perspectives on the issues in the five papers that constitute the main series. It is worth noting that even in the first paper in this series, Toulmin is mentioned several times as holding a view similar to the view that Hitchcock is developing (see especially 1985: 94). The identification of covering generalizations with Toulmin warrants becomes most explicit and most prominent in the 1998 and 2003 papers.

${ }^{11}$ Hitchcock (1992: 112) says that "arguments where we look for truth preservation between premisses and conclusion" may be called "conclusive arguments." See also Hitchcock 1994: 5859, where he says that such arguments exhibit 'conclusive validity.' It is worth noting that the official topic of Hitchcock 1985 is "enthymematic arguments" and in its opening paragraphs it explicitly exempts from consideration arguments "appropriately appraised by a non-deductive standard". Hitchcock 1998 does not explicitly exclude such arguments from consideration, but it is clear that so-called "non-deductive arguments" would not qualify as arguments in which the conclusion follows from the premisses on the "revised generic conception of consequence" formulated on p. 26 of that paper. 
${ }^{12}$ Hitchcock offers two reasons why the "assumption" of an enthymematic argument must generalize over a content expression occurring in both premisses and conclusion. (1) According to 1985: 87, unless there is a repeated content expression common to premisses and conclusion, the premisses will not be "topically relevant" to the conclusion and the argument will be a nonsequitur. (2) According to Hitchcock 1992: 111-112, we ought (following Bolzano) to rule out "trivial cases in which there is no counter-example because no substitution could make the premisses true or no substitution could make the conclusion false." So he adds the requirement that at least one substitution on the variable content makes the premisses true and at least one substitution makes the conclusion false. "A consequence of these added requirements is that an argument with a good inference has a content expression repeated in a premise and the conclusion" (1992: 112).

${ }^{13}$ Hitchcock envisages cases where we would also want to generalize over additional content expressions that occur only in the premises-see the marijuana/alcohol example that occurs in Hitchcock 1985: 92-93.

${ }^{14}$ With reference to an example on 1985: 93, Hitchcock says, "The context of utterance of the ... argument indicates that we should generalize the associated conditional only over the class of words ending in '-ing'. Doing so we get the sentence, 'For any word ending in '-ing', if it is the subject of the sentence then it is a gerund' or, in more standard English, 'Every word ending in 'ing' which is the subject of a sentence is a gerund." That is to say, formulating a covering generalization for an argument may require making certain considerations explicit which are not explicit in the text with which we are working but whose bearing may be inferred from features of the context from which that text is drawn.

${ }^{15}$ Hitchcock has communicated to me that he considers the omission of this point from the published version of the 1985 paper to have been an unfortunate oversight.

${ }^{16}$ The phrase "generic theory of consequence" appears only in the 1998 paper. That paper recognizes five conceptions of logical consequence (the deducibility conception, the modal conception, the substitutional conception, the formal conception and the model-theoretic conception). In previous papers (e.g., 1985 or, in part, 1994), Hitchcock had tended to couch his points in substitutional terms. The "official" formulation in Hitchcock 1998: 26 is phrased so as to be applicable to three of the five conceptions (the substitutional, the formal and the modeltheoretic)—hence the phrase "generic conception of consequence."

${ }^{17}$ Hitchcock (1985:86-87) had suggested that an argument is a non-sequitur if the only way to show that its associated conditional is true is by showing that its conclusion is true.

${ }^{18}$ If we make the kinds of moves made in Sellars 1953 and especially Chapter 11 of Sellars 1963, the possible worlds in which our laws of nature hold will coincide with the set of semantically possible worlds (where the "meaning postulates" or p-rules that pick them out are the meaning postulates of our language). In a very early paper ("Concepts as involving laws and inconceivable without them," Sellars 1948), he had considered and rejected the possibility of making sense of nomically necessary conditionals by construing them as true in some subset of possible worlds. The alternative that emerged 10 years later is the sort of view set out in Sellars 1953 and in chapter 11 of Sellars 1963 (which had first appeared as a paper in Philosophy of Science in 1954).

${ }^{19}$ See for example the arguments for the need to recognize "material inferences" in Sellars 1953those arguments rest on the need for subjunctive conditionals in empirical science.

${ }^{20}$ In another context, Mark Weinstein (2002: 166-67) has proposed, for example, that we recognize a "range of entailment kinds" from logical entailments to "weak entailments that are no more than suggestive," and that "we might expect for each entailment kind a linked implication relation based either on an appropriately modalized warrant, or alternatively, on appropriately characterized inference tickets." He has, he says, "explored in detail how such a relationship could be given rigorous metamathematical content for entailments that depend on theoretic depth and breadth, modeled on the entailments within mature physical sciences." Weinstein 2002 only broaches 
these ideas in summary fashion, but see the references there to five of Weinstein's papers where they are developed more fully.

${ }^{21}$ Consider, for example, the claim that a CG (for example, of the form: for any $\mathrm{x}$ if Fx then Gx) holds only presumably or presumptively. That can't be taken to mean that we may presume that for any $\mathrm{x}$ if $\mathrm{Fx}$ then $\mathrm{Gx}$. As soon as one discovered an object that was $\mathrm{F}$ but not $\mathrm{G}$, one would no longer be entitled to make such a presumption. Presuming cannot be "applied to" the CG as a whole - the universal quantifier cannot occur within the scope of the presumption. Rather, the reference to presumption must fall within the scope of the universal quantifier. One must modify the CG to say something like: for any $\mathrm{x}$, if Fx then $\mathrm{x}$ is presumably a G. But that, I think, will come down to saying: if you know something is an $\mathrm{F}$, then you may presume it to be a $\mathrm{G}$-in which case, one's CG will turn out to be the sort of warrant that I describe in Part 5 of this paper.

${ }^{22}$ E.g., one might hold that good arguments are the ones that are truth-preserving and that arguments can justify their conclusions just because they are truth-preserving.

${ }^{23}$ I take it to be relatively uncontroversial that "acceptability" epistemically understood is a necessary condition of premiss adequacy. For a defense of the idea that it is also a sufficient condition of premiss adequacy, see Pinto 2001: 23-26 and Pinto 2003a.

${ }^{24}$ At least if we're thinking of what Pollock (2001: 235) calls rebutting defeaters and what I (2001: 28) call overriding defeaters. For whenever an argument has true premisses and a false conclusion, there will be a host of true propositions which "rebut" its conclusion-i.e., from which the negation of its conclusion follows or could be inferred. Hence, on the assumption that the mere truth of a rebutter defeats a defeasible inference, virtually every defeasible inference with a false conclusion will turn out to be defeated.

${ }^{25}$ For one thing, Chisholm $(1957,1966$ and 1977) works with a small number of such principles, few of which throw much light on the "material" inferences I'm interested in, whereas Toulmin warrants - as Hitchcock has recognized-hold out the promise of illuminating such inferences. For another, Chisholm's account of the authority of such principles leads either to the claim that they are synthetic a priori propositions (see the hint of this in Chisholm 1957: 112 ) or to something that resembles Moore's various attempts to defend common sense (see Chisholm on the "problem of the criterion" in Chapter 4 of 1966 and chapter 7 of 1977).

${ }^{26}$ In fact this last form of words echoes the way in which rules of inference are standardly formulated in expositions of classical formal logic_-as far back, at least, as the Preface to the second edition of the Principia Mathematica.

${ }^{27}$ Toulmin wants to distinguish between the force of such terms, which is "field invariant," and the criteria for their use, which varies from field to field. Since there are notorious difficulties in pinning down the meaning of the "field" (Toulmin's definition in terms of "logical types" (2003 /1958: 14) isn't much help, and moreover doesn't fit what he often seems to have in mind when he himself uses the term - namely disciplines.) One might do better to say that the force of such terms is context independent, while the criteria for their use will vary from context to context. ${ }^{28}$ Note especially his remark that the modal operators "are best understood...by examining the functions they have when we come to set out our arguments" (2003/1958: 17).

${ }^{29}$ Lurking in the background here is the account Austin gives in "Other Minds" of what we do when we say 'I know'. (Austin 1970: 99): "When I say 'I know', I give others my word: I give others my authority for saying that 'S is P."' By virtue of lending my authority unguardedly, I make myself liable for criticism should what I lent my authority to prove false-in that event I am "liable to be rounded on by others" (Austin, p. 100). But if I lend my authority guardedly-if I say only "I am sure" and do not say "I know", then according to Austin I'm not liable to be "rounded on." Something analogous is true in Toulmin's account of "Probably S is P"- -see 2003/ 1958: 53-57. Though I don't endorse Toulmin's account of 'probably' in all its details, I do hold a view that is similar to it (see the final sentence in note 30 below.) 
${ }^{30}$ When discussing the modal qualifiers, Toulmin makes it quite clear that employing them does not yield sentences which refer to doxastic attitudes: "saying 'S is probably $\mathrm{P}$ ' is not saying 'I am fairly confident, but less than certain, that S is P', for 'probably' does not belong to this series of words.... When I say 'S is probably P', I commit myself guardedly, tentatively or with reservations to the view that $S$ is $P$, and (likewise guardedly) lend my authority to that view" (2003/1958: 49). However, he concedes (to the proponent of the "subjective" interpretation of probability) that "He [the subjectivist] has noticed one thing (perhaps the only one) which is always the case whenever the word 'probably', or one of its derivatives, is used correctly: everyone who says and means 'Probably $p$ ' does believe confidently that $p$ " (p. 59). In this regard, he is adopting a view about 'probably' that my co-authors and I adopted in Pinto, Blair and Parr 1993: 95-97—that 'probably' is an "assertion qualifier" and that, although in saying 'Probably $p$ ' we may in some sense be expressing our "belief attitude" toward what we are claiming, the claim we are putting forward or asserting is $p$.

${ }^{31}$ Section 4 of Hitchcock 2005 accommodates defeaters in essentially the same way.

${ }^{32}$ In Toulmin's account, the authority of warrants - considered as "general morals of a practical character" (2003/1958: 98) - arises from their backing. But—as I read Toulmin—that authority is also rooted in the goals they are to serve (see Toulmin et al. 1984/1979: 274-276 and at various junctures in Chapters 26-30 of that work).

${ }^{33}$ The idea that the principles in terms of which we evaluate arguments and inferences should be relative to persons (and also to times) is consistent with the views about argument appraisal defended in my early paper "Logic, epistemology and argument appraisal," first presented in 1989 and reprinted as Chapter 3 of Pinto 2001. Notice also that the form I'm proposing would leave us the option of restricting the domain of values which the quantificational variables might take. We might, for example, restrict the applicability of a warrant to the members of one or another professional community.

${ }^{34}$ It is not difficult to see how to enhance this preliminary account of the form of warrants to make provision for arguments and inferences with two or more premisses towards which an individual might have different doxastic attitudes-for example, someone drawing an inference about whether Reilly is married might be quite sure that Reilly is a Catholic priest, but only presume that he is not an Eastern rite priest. The need for antecedents with more than one "it is reasonable for $\mathrm{S}$ to ..." clauses will also arise if we should want to have warrants that take us from a desire and a belief to an intention. See point (b) on p. 259.

${ }^{35}$ Sosa's insistence on the importance of "reflective knowledge" can be seen as a partial recognition of this point, or a first step in its direction. See "Knowledge and intellectual virtue" in Sosa 1991: 225-244. (esp. pp. 239-242) and also "Intellectual virtue in perspective" in Sosa 1991: 270-93 (esp. p. 290) .

${ }^{36}$ In "The relation of argument to inference," I attempt to trace a possible evolution of the concept of inference through a series of 6 steps (Pinto 2001: 42-43). What I've just pointed out corresponds to steps 2 and 3 of that process. That paper recognizes further stages in the evolution of critical practice and in our concept of inference-most importantly, a step in which " $[\mathrm{w}] \mathrm{e}$ move ... to a broadened conception of criticism, one not tied quite so closely to logical rules or material principles of inference, but modelled in part on the discussions of the probative value of evidence that occur in contexts where articulable rules are not available." I'm still inclined to think that our critical practice extends beyond the realm for which we are able to formulate anything like rules of inference-a realm in which nevertheless "the value of [our] inferences is not something that is just arbitrarily accepted; rather it is something open to discussion and rational evaluation." Quotations are from page 43 of Pinto 2001.

${ }^{37}$ Brandom has insisted on the "expressive" role of logical vocabulary. Thus he has recently said: "Instead of seeing conformity with logical truths as what rationality consists in, one can see 
logical vocabulary as making possible the explicit codification of meaning-constitutive inferential relations. On such an expressive view of the function of logic, the task characteristic of logical locutions as such is to let us say, in the form of explicit claims, what otherwise we could only donamely, endorse some material inferential relations and reject others. Prior to the introduction of the conditional, for instance, one can implicitly take or treat the material inference (in any of the three senses botanized above [commitment-preserving, entitlement-preserving, and inferences reflecting incompatibility relations] from $p$ to $q$ as a good or bad one, endorsing or rejecting it in practice. Once a suitable conditional is available, though, one can explicitly claim that $p$ entails $q$. And explicit claims are the sort of thing we can reason about, ask for evidence or arguments for. The expressive job of specifically logical locutions is to make inferential relations explicit, to bring them into the game of giving and asking for reasons as things whose own rational credentials are available for inspection and criticism." Brandom 2002: 9. The view is developed more fully in Chapter 1 of Brandom 2000 and Chapter 2 of Brandom 1994.

However, the conditionals that Brandom appears to have in mind differ in a crucial respect from the sort of warrant statements I have in mind. My conditionals render explicit both the entitlement to a propositional attitude and the specific type of propositional attitude to which the entitlement applies. There is no indication that the conditionals Brandom has in mind render explicit anything beyond the relationships holding between the propositional contents of those attitudes. This is rooted, I think, in the nature of Brandom's overall project, which is - to put it crudely - to model all intentional states and statuses on what is required to make sense of linguistic performances, while taking assertion to be the prototypical speech act. The content of an assertion is to be understood in terms of (a) what other assertions it commits us to (downstream, in his terms) and (b) what other assertions (upstream, in his terms) can entitle us to it (i.e. can be offered as reasons for it). Since assertion is an on/off concept, his account does not lend itself to "reconstructing" the functionally type-identified variations in doxastic attitude that are central to my account. At this point, it is not at all clear to me what the effect would be on Brandom's project if you tried to include in it the recognition of functionally type-identified varieties of "guarded" assertion. It might amount to a fairly minor addition or emendation; but then again, it might upset the applecart. ${ }^{38}$ Since I'm not about to claim that any such principle is "true by definition," no "naturalistic fallacy" lurks in the bushes here. Moreover, my view is that using the word 'good' without scare quotes to characterize something which serves a purpose is appropriate only if one endorses the purpose which it serves. It is only in virtue of a positive evaluative attitude toward a purpose that characterizing the "means" to it as 'good' has genuine normative force. This is, I think, the fundamental insight of prescriptivism - though the point need not be developed in quite the same terms as those in which prescriptivists have developed it.

Moreover, one's evaluation of a means as good is reasonable only if one's evaluative attitude toward the purpose it serves is itself reasonable. It is a component of my view of reasons that there can be reasons for such evaluative attitudes—see Pinto 2003c for this point—and that therefore such attitudes can be, or fail to be, reasonable.

${ }^{39}$ In the paper 'Reasons' (Pinto 2003b: 7-8), I distinguished between reasons for believing or accepting something and grounds on which we do or might accept it. I called attention to "pragmatic reasons" for believing (represented, for example, by the argument in Pascal's wager), and suggested that the mark of such pragmatic reasons is that they don't contain grounds for belief or evidence for what is to be believed. Although I contrasted pragmatic reasons with reasons containing grounds for believing, in that paper I did not explain the basis of the distinction between the two sorts of reasons. I will say here that "pragmatic reasons" for a belief are reasons which serve purposes that don't require that what is believed to be true, close to the truth, or likely to be true. ${ }^{40}$ I.e., the occasions on which the antecedent of the "rule" which captures the practice would apply.

${ }^{41}$ See the examples in Pinto 2003b: 5-6 and 13-14. For a similar or related point, see Freeman 2003 
(which draws on ideas to be found in Clarke 1989) and Freeman 2005: 62.

${ }^{42}$ Compare Brandom's use of a similar point in his assessment of reliability theories of perceptual knowledge-for example in Chapter 3 of Brandom 2000.

${ }^{43}$ I am trying to characterize what the "objective virtue" of a rule of inference consists in. I am not attempting here to give an account of how we know — or how we can have reason to believe - that a proposed rule is reliable in the sense defined. But let me point out that, if this account of the "objective virtue" of warrants is correct, we are in a position to know that a proposed warrant is reliable only if we are in a position to estimate the order of magnitude of certain objective likelihoods. One way of getting in a position to do that is to carefully tally the relative frequency of success resulting from the application of the rule (and to infer that the relative frequency in our sample reveals the order of magnitude of the objective likelihood required for reliability). It is my impression, however, that we seldom base our estimates of objective likelihood on careful tallies of relative frequencies, and that we almost never do so when deciding which inferential practices or strategies are good ones. It is essential to remember, therefore, that although having a careful tally of a relative frequency may be a sufficient condition for having a reason for adopting an estimate of objective likelihood, it is not a necessary condition for having such a reason.

${ }^{44}$ See the Postscript to Siegel 1988 (127-137), which develops two principal objections to a means-ends conception of rationality: (i) that it is unable "to assess the rationality of ends" (p. 130) and (ii) that it "threatens to rule out some sorts of reasons in favor of prudential or efficiency considerations" (p. 131). I agree with Siegel on both these points. However, they do not apply to the position I am defending here. With regard to (i), see note 38 above concerning the position I take with respect to means-end evaluations. With regard to (ii), my current position is that ends are indeed constitutive for the existence of reasons (the existence of reliable rules of inference is a necessary condition for the existence of reasons, and rules can be judged reliable only in relationship to the ends that inferential practices serve). However, it does not follow from that position that every reason is of the means-end variety-i.e., it does not follow that the propositional content of the antecedent of every rule of inference concerns a means-end relationship.

${ }^{45}$ Siegel 1996 deals with attempts by Giere and Laudan to reduce specifically epistemic normativity to instrumental rationality. My view is not subject to the arguments Siegel advances against Laudan and Giere in that paper. For one thing, my view recognizes rules of inference which take the form of "categorical" epistemic norms, and is therefore not subject to the central argument Siegel advances, which turns on whether all epistemic norms take the form of "instrumental" reasons. For another, the view propounded here simply does not reduce to a "crude" or "whatever works" pragmatism with respect to epistemic goodness, since the goal or purposes which ground the reliability of inferential practices are to consist in purposes which (a) require the adoption of doxastic attitudes to propositional contents and which (b) are sensitive to whether those propositional contents are true.

${ }^{46}$ Weinstein (2002: 178-79) has raised important questions about the use I tried to make of the notion of cognitive communities, and their relation to critical practice, in Chapter 13 of Pinto 2001. A satisfactory account of the purposes served by inferential practices would require me to address those questions in a systematic way. It would also require me to deal with the relationship of the norms that hold sway within the cognitive communities associated with specific disciplines both (a) to individual practical reasoning outside those disciplines and (b) to argumentative discourse in the public sphere. 


\section{References}

Anscombe, G. E. M. (1957). Intention. Oxford: Basil Blackwell.

Austin, J. L. (1970). Other Minds. In J.L. Austin, Philosophical Papers, second edition. J.O. Urmson and G.J. Warnock (Eds.), (London: Oxford University Press): 76-116. This paper first appeared in the Proceedings of the Aristotelian Society, Supplementary Edition in 1946.

Blair, J. Anthony. (2003). Towards a Philosophy of Argument. In J. A. Blair et al. (Eds.), Informal Logic at 25: Proceedings of the Windsor Conference. CD-ROM (Windsor, ON: Ontario Society for the Study of Argumentation).

Brandom, Robert. (1994). Making It Explicit. Cambridge, Mass.: Harvard University Press.

Brandom, Robert. (2000). Articulating Reasons: An Introduction to Inferentialism. Cambridge, Mass.: Harvard University Press.

Brandom, Robert. (2002). Tales of the Mighty Dead: Historical Essays in the Metaphysics of Intentionality. Cambridge, Mass.: Harvard University Press.

Chisholm, Roderick. (1957). Perceiving: A Philosophical Study. Ithaca NY: Cornell University Press.

Chisholm, Roderick. (1966). Theory of Knowledge. Englewood Cliffs, NJ: Prentice-Hall.

Chisholm, Roderick. (1977). Theory of Knowledge, second edition. Englewood Cliffs, NJ: Prentice-Hall.

Clarke, D.S., Jr. (1989). Rational Acceptance and Purpose: An Outline of a Pragmatist Epistemology. Totawa, NJ: Rowan and Littlefield.

Eemeren, F.H. van, J.A. Blair, C. A. Willard and A.F. Snoeck Henkemans (Eds.). (2003). Anyone Who Has a View: Theoretical Contributions to the Study of Argumentation. Dordrecht: Kluwer.

Freeman, James. (2003). The pragmatic dimension of premise acceptability. In van Eemeren et. al. 2003.

Freeman, James. (2005). Acceptable Premises: An Epistemic Approach to an Informal Logic Problem. Cambridge University Press.

George, Rolf. (1972). Enthymematic Consequence. American Philosophical Quarterly 9(1): 113-116.

George, Rolf. (1983). Bolzano's Consequence, Relevance, and Enthymemes. Journal of Philosophical Logic 12(3), 299-318.

Goldman, Alvin. (1988). Epistemology and Cognition. Cambridge, MA: Harvard University Press.

Goldman, Alvin. (1999). Knowledge in a Social World. Oxford: Oxford University Press.

Goldman, Alvin. (2002). The Unity of the Epistemic Virtues. In Alvin Goldman, Pathways to Knowledge: Private and Public, 51-70. Oxford: Oxford University Press.

Govier, Trudy. (1987). Four reasons there are no fallacies. As excerpted and revised in Hansen and Pinto (Eds.), Fallacies: Classical and Contemporary Readings, 172180, under the title "Reply to Massey" (University Park, PA: Pennsylvania State Press, 1995). First appeared as Chapter 9 of Trudy Govier, Problems in Argument Analysis and Evaluation (Dordrecht Holland and Providence RI: Foris, 1987). 
Hansen, Hans V. and Robert C. Pinto (Eds). (1995). Fallacies: Classical and Contemporary Readings. University Park, PA: Pennsylvania State University Press.

Hitchcock, David. (1985). Enthymematic arguments. Informal Logic 7: 83-97.

Hitchcock, David. (1992). Reasoning by analogy: A general theory, in Stephen P. Norris (Ed.), The Generalizability of Critical Thinking: Multiple Perspectives on an Educational Ideal (New York: Teachers College Press), 109-224.

Hitchcock, David. (1994). Validity in conductive arguments. In Ralph H. Johnson and J. Anthony Blair, (Eds.), New Essays in Informal Logic (Windsor, ON: Informal Logic): 58-66.

Hitchcock, David. (1998). Does the traditional treatment of enthymemes rest on a mistake? Argumentation 12: 15-37.

Hitchcock, David. (2001). Sampling scholarly arguments: a test of a theory of good inference. In Hans V. Hansen, Christopher Tindale and Christopher Kirwin (Eds.), Argumentation at the Century's Turn CD-ROM (St. Catharines, ON: Ontario Society for the Study of Argumentation).

Hitchcock, David. (2002). A note on implicit premisses. Informal Logic 22: 159-60.

Hitchcock, David. (2003). Toulmin's Warrants. In van Eemeren et. al., 2003: 69-82.

Hitchcock, David. (2005). Good Reasoning on the Toulmin model. In D. Hitchcock (Ed.), The Uses of Argument: Proceedings of a Conference at McMaster University, 1821 May, 2005 (Ontario Society for the Study of Argumentation).

Peirce, Charles S. (1955). Philosophical Writings of Peirce, Justus Buchler (Ed.). New York: Dover Publications.

Pinto, Robert C, J. Anthony Blair and Katherine E. Parr. (1993). Reasoning: A Practical Guide for Canadian Students. Scarborough, ON: Prentice Hall Canada. A U.S. edition was published the same year as Pinto and Blair, Reasoning: A Practical Guide (Englewood Cliffs, NJ: Prentice Hall).

Pinto, Robert C. (2001). Argument, Inference and Dialectic. Dordrecht: Kluwer Academic Publishers.

Pinto, Robert C. (2003a) Truth and Premiss Adequacy. In Hans V. Hansen, et al., (Eds.) Argumentation and its Applications CD-ROM (Windsor, ON: Ontario Society for the Study of Argumentation).

Pinto, Robert C. (2003b). Reasons. In van Eemeren et. al. (Eds.), 2003: 3-15.

Pinto, Robert C. (2003c). The uses of arguments in communicative contexts. In J. A. Blair et al., (Eds.), Informal Logic at 25: Proceedings of the Windsor Conference. CDROM (Windsor, ON: Ontario Society for the Study of Argumentation).

Pollock, John. (2001). Defeasible reasoning with variable degrees of justification. Artificial Intelligence 133: 233-282.

Quine, Willard van Orman. (1953). From a Logical Point of View. Cambridge, Mass.: Harvard University Press.

Quine, Willard van Orman. (1960). Word and Object. Cambridge, Mass.: M.I.T. Press.

Rescher, Nicholas. (1988). Rationality. Oxford: Clarendon Press.

Searle, John. (1979). Expression and Meaning: Studies in the Theory of Speech Acts. Cambridge: Cambridge University Press. 
Sellars, Wilfrid. (1948). Concepts as involving laws and inconceivable without them. Philosophy of Science 15: 287-315.

Sellars, Wilfrid. (1953). Inference and meaning. Mind (New Series) 62: 313-338.

Sellars, Wilfred. (1963). Science, Perception and Reality. London: Routledge \& Kegan Paul.

Sellars, Wilfrid. (1968). Science and Metaphysics: Variations on Kantian Themes. London: Routledge \& Kegan Paul.

Siegel, Harvey. (1988). Educating Reason: Rationality, Critical Thinking and Education. London and New York: Routledge.

Siegel, Harvey. (1996). Instrumental rationality and naturalized philosophy of science. Philosophy of Science 63 (Proceedings): S116-S124.

Sosa, Earnest. (1991). Knowledge in Perspective: Selected Essays in Epistemology. Cambridge: Cambridge University Press.

Toulmin, Stephen. (2003). The Uses of Argument, Updated edition Cambridge: Cambridge University Press. The first edition of this work was published in 1958.

Toulmin, Stephen, Richard Rieke and Allan Janik. (1984). An Introduction to Reasoning, Second Edition. New York: Macmillan. First edition was published in 1979.

Weinstein, Mark. (2002). Critical review of Robert C. Pinto's Argument, Inference and Dialectic. Informal Logic 22: 161-180.

Robert C. Pinto Centre for Research in Reasoning, Argumentation and Rhetoric Department of Philosophy

University of Windsor Windsor, ON, N9B 3P4

pinto@uwindsor.ca 